\title{
elsevier_BC_4514
}

\section{The conceptus regulates tryptophanyl-tRNA synthetase and superoxide dismutase 2 in the sheep caruncular endometrium during early pregnancy}

K.H. Al-Guborya,*

kais.algubory@jouy.inra.fr

M. Arianmanesh ${ }^{b}$

C. Garrel ${ }^{c}$

P.A. Fowler

aINRA, UMR1198 Biologie du Développement et Reproduction, Département de Physiologie Animale et Systèmes d’Elevage, F-78350 Jouy-en-Josas, France

${ }^{b}$ Department of Anatomical Sciences, School of mMedicine, Zanjan University of Medical Sciences, Zanjan, Iran

'Unité de Biochimie Hormonale et Nutritionnelle, Centre Hospitalier Universitaire de Grenoble, Département de Biologie Toxicologie_-Toxicologie - pharmacologie, 38043 Grenoble cedex 9, France

IInstitute of Medical Sciences, Division of Applied Medicine, University of Aberdeen, Foresterhill, Aberdeen AB25 2ZD, UK

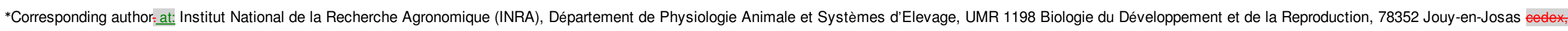
FraneeCedex, France. Tel.: +33 1 34652362; fax: +33 134652364 .

\section{Abstract}

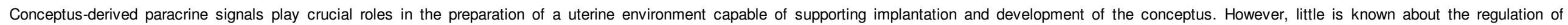

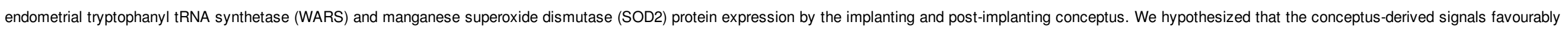

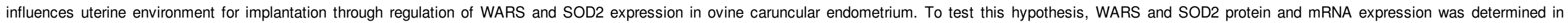

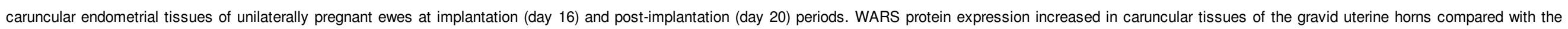

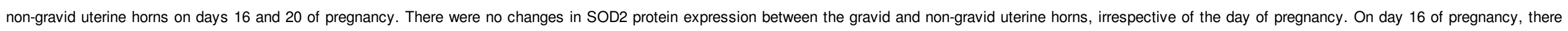

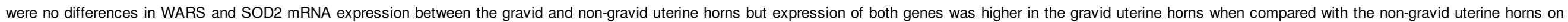

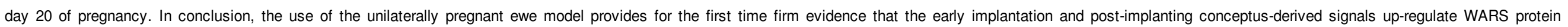
expression within the caruncular endometrium. Further studies are necessary to identify these signalling molecules and to understand mechanisms whereby they exert paracrine action within the endometrium.

Keywords: Sheep; Endometrium; Tryptophanyl tRNA synthetase; Manganese superoxide dismutase; Early pregnancy

\section{Introduction}

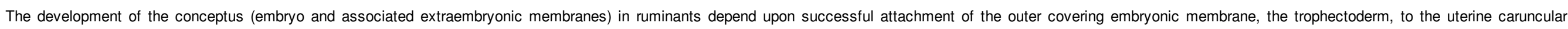

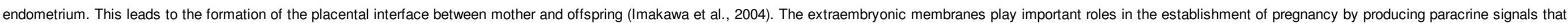

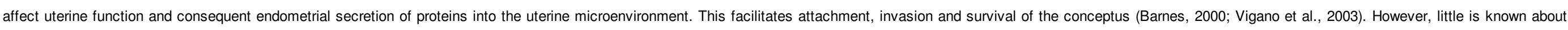

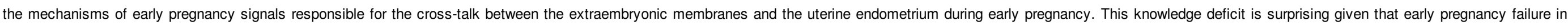
sheep (Dixon et al., 2007) and cattle (Diskin and Morris, 2008) reduces reproductive performance and lowers production and economic efficiency.

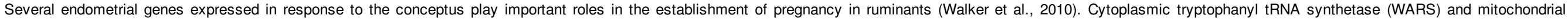

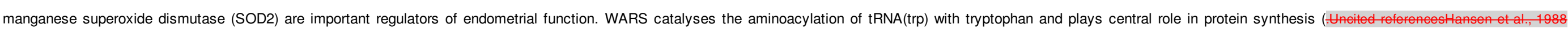




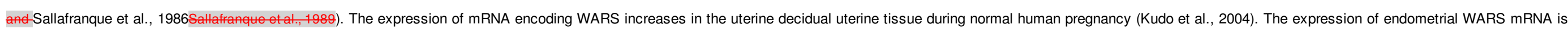

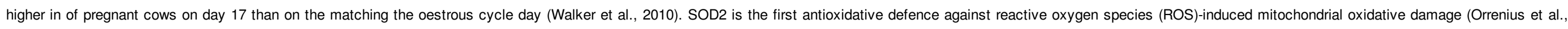

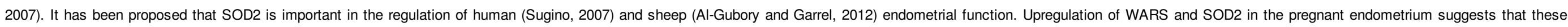

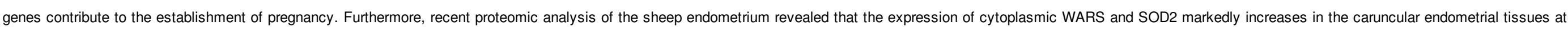

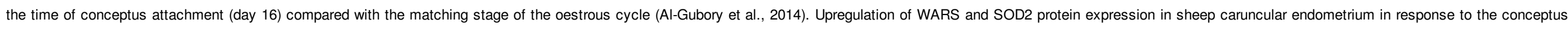
during early pregnancy may be an important mechanism to ensure the establishment of pregnancy.

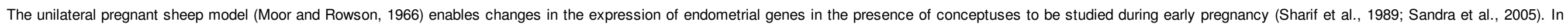

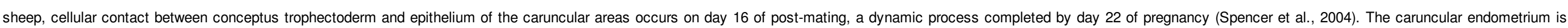

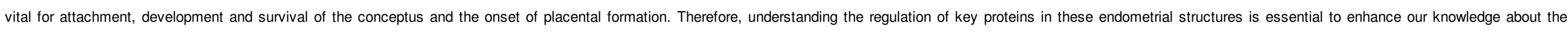

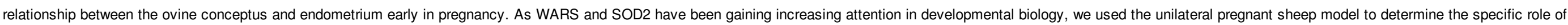

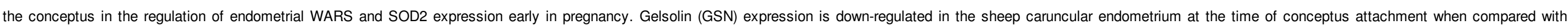

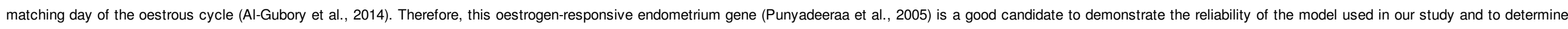
the specific role of the conceptus in the regulation of specific proteins of interest.

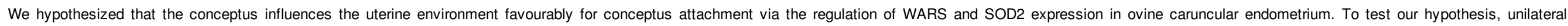

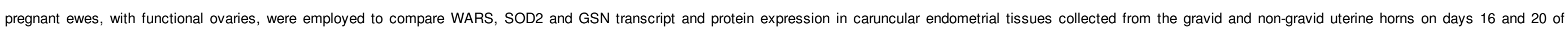
pregnancy corresponding to early conceptus attachment and post-attachment periods, respectively.

\section{Materials and Mmethods}

\subsection{Animals and surgery}

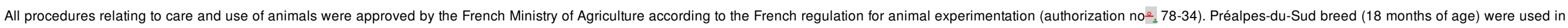

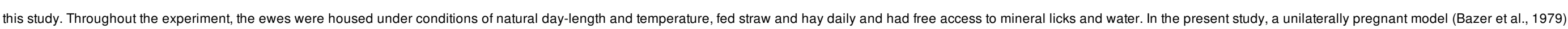

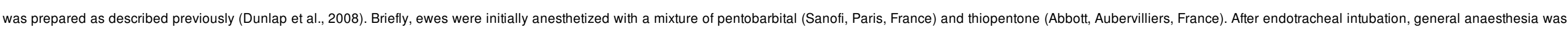

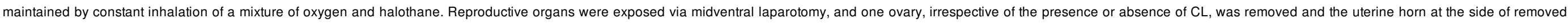

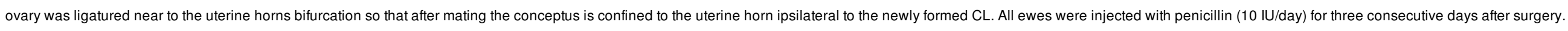

\subsection{Animal oestrus synchroniszation and mating}

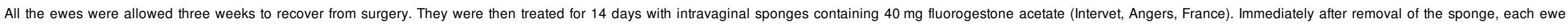
received s an intramuscular injection of $400 \mathrm{IU}$ of equine chorionic gonadotropin (eCG, Intervet). Mating was performed at the time of the synchronized oestrus with fertile rams of the same breed, at an interval of $12 \mathrm{~h}$.

\subsection{Tissue collection}

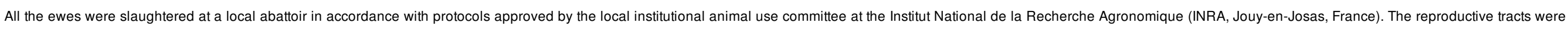

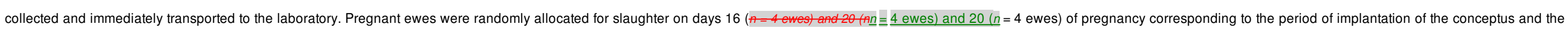

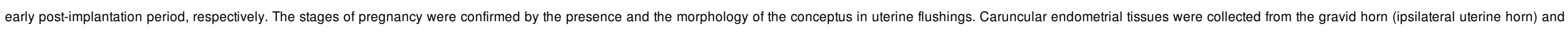
non-gravid horn (contralateral uterine horn) of each ewe. Immediately after dissection, tissues were snap-frozen in liquid nitrogen and stored at $-80^{\circ} \mathrm{C}$ until processed.

\subsection{RNA isolation and quantification}

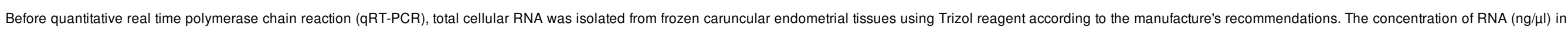

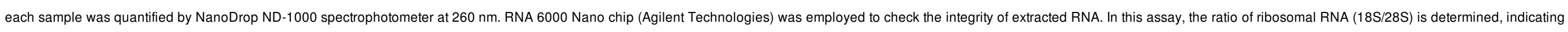




\section{elsevier_BC_4514}

the integrity of the isolated RNA samples.

\subsection{Quantitative real time polymerase chain reaction (qRT-PCR)}

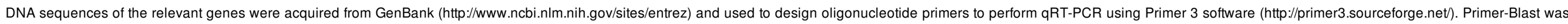

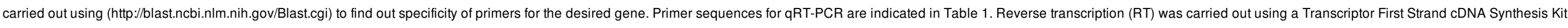

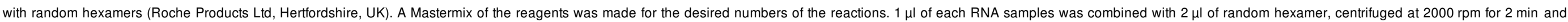

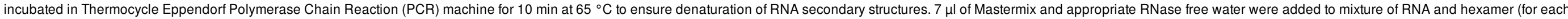

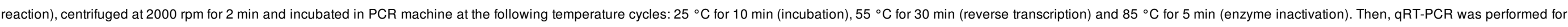
samples with and without reverse transcriptase for each gene in duplicate. The amplified final products of qRT-PCR were electrophoresed on $2 \%$ agarose gel.

Table 1 Primer sequences used for quantitative RT-PCR analysis.

\begin{tabular}{|c|c|c|}
\hline Genes & Forward primer & Reverse primer \\
\hline WARS & AGCATCGCTGCTCAGGGGGA & TGGCATCCAGGCCCTCACCA \\
\hline SOD2 & AGCCCCAACGGTGGTGGAGA & AGCCAAGCCAACCCCAACCG \\
\hline GSN & CTAATCGTGACCGGCGGAC & CAGACCAATAGTTGTCATCCCAGC \\
\hline CYP & CATTCTGAAGCATACAGGTCCTG & TCCATGGCTTCCACAATATT \\
\hline
\end{tabular}

Abbreviations: WAPS, GAbbreviations: WARS, cytoplasmic tryptophanyl tRNA synthetase; SOD2, mitochondrial manganese superoxide dismutase; GSN, Gelsolin; CYP, cyclophilin.

\subsection{Western blot}

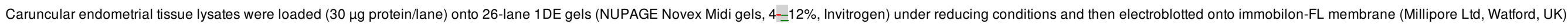

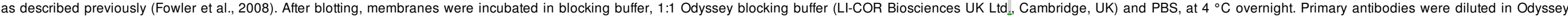

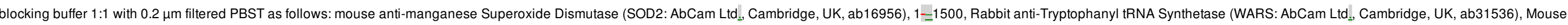

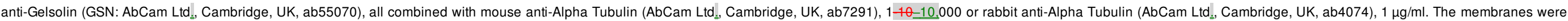

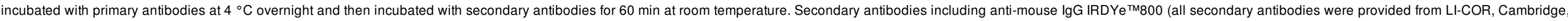

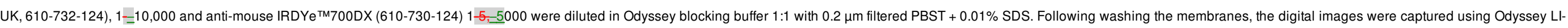
COR Infrared Imager (LI-COR, Cambridge, UK). The band volumes and molecular weights (KDa) were then obtained following a background subtraction using Phoretix-1D Advanced software (Nonlinear Dynamics).

\subsection{Assay of SOD2 activity}

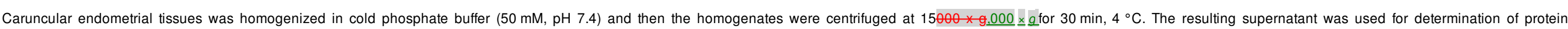

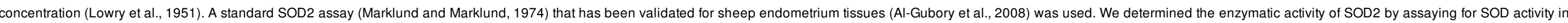

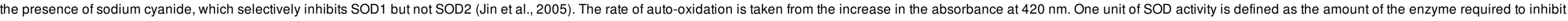
the rate of pyrogallol auto-oxidation by $50 \%$.

\subsection{Statistical analysis}

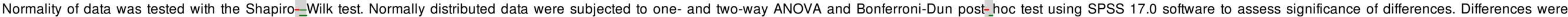
considered significant at $\underline{\underline{P}}<0.05$.

\section{Results}




\section{elsevier_BC_4514}

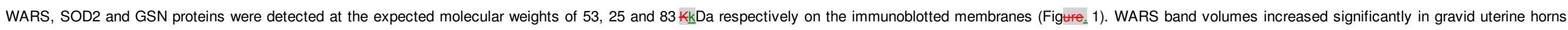

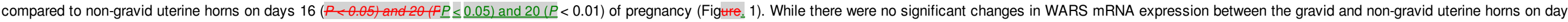

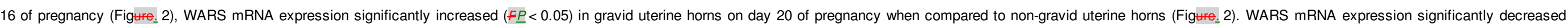
$(P \underline{P}<0.05)$ from day 16 to day 20 of pregnancy in non-gravid uterine horns (Figure, 2).

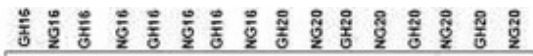
WARS, $53 \mathrm{KOa}$ otubulin, $50 \mathrm{KDO}$
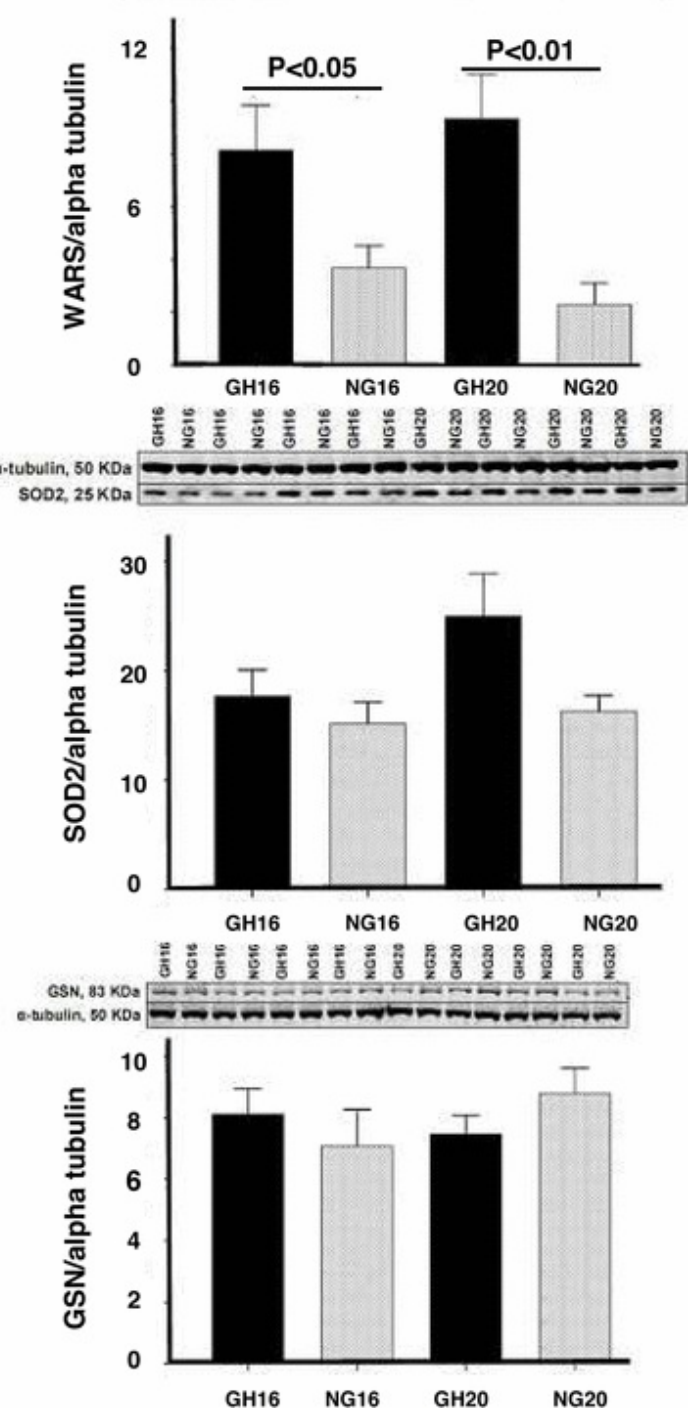

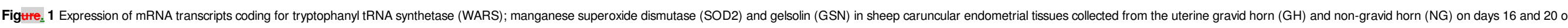
pregnancy. Data was normaliszed against the expression levels of cyclophilin gene. Data are shown as means \pm SEM for four ewes per group. The acceptable level of significance was set at $P<0.05 . F i g u t r e \underline{P} \leq \underline{0.05}$. 
elsevier_BC_4514
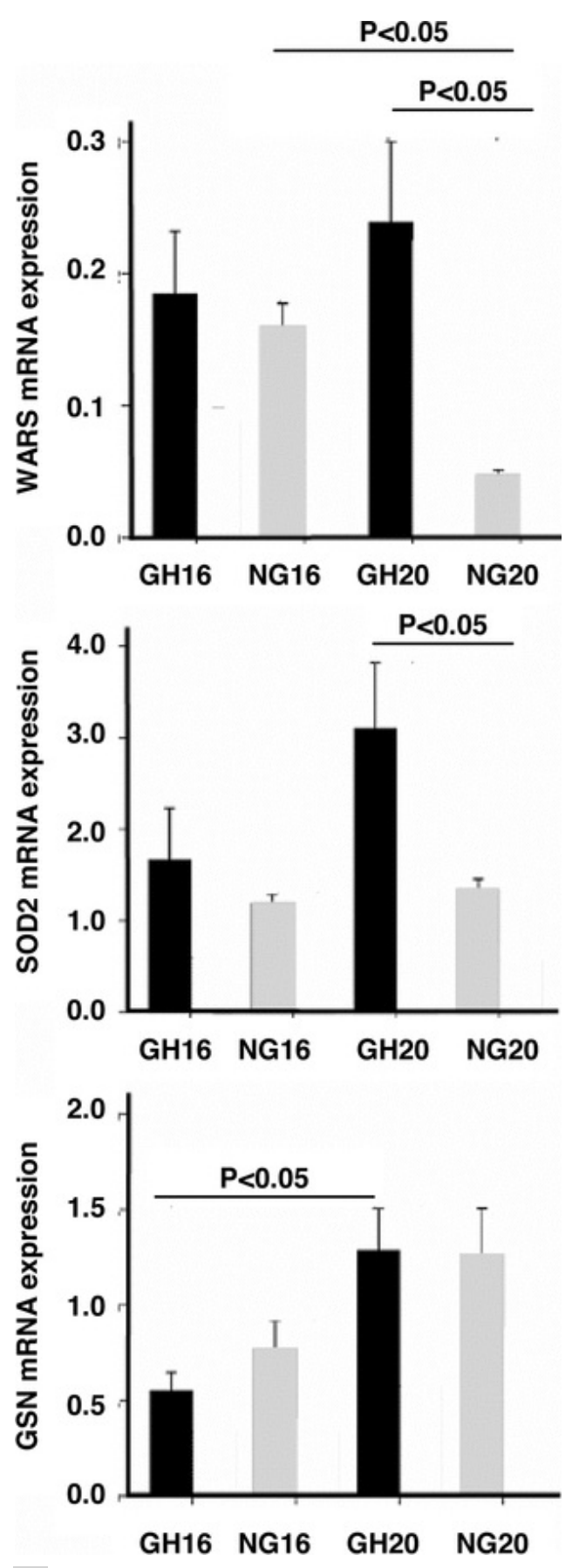

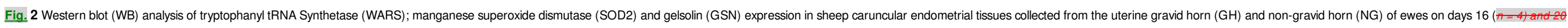

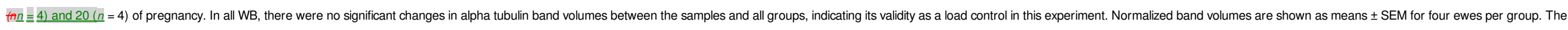




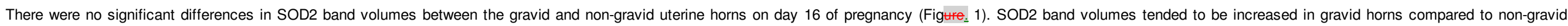

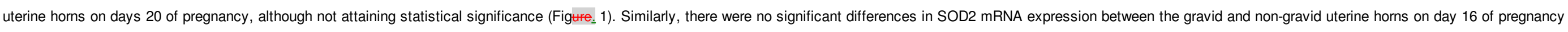

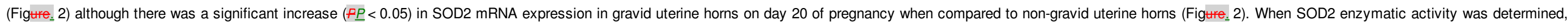

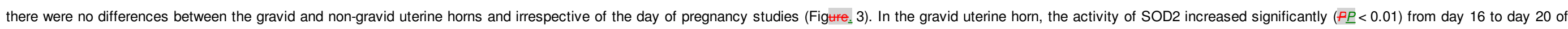
pregnancy (Figure. 3).

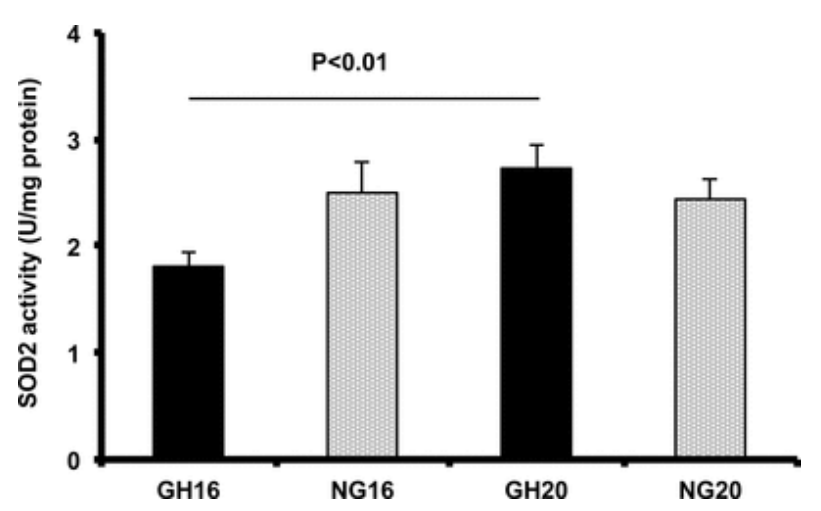

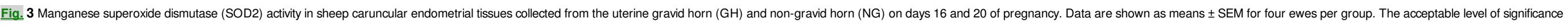
was set at $P<0.05$. Figure $\underline{P} \leq \underline{\underline{0.05}}$.

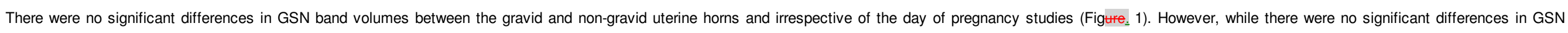

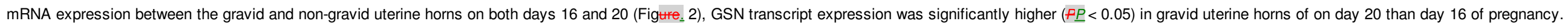

\section{Discussion}

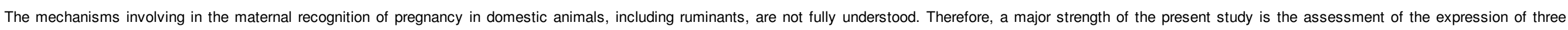

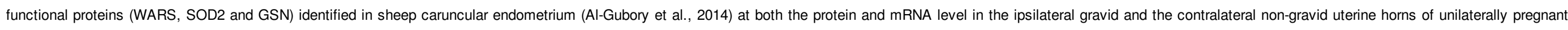

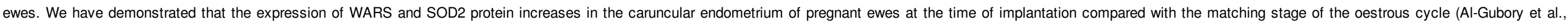

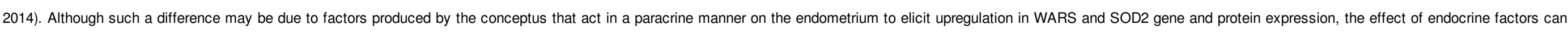

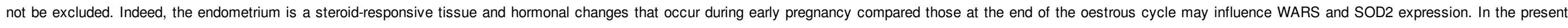

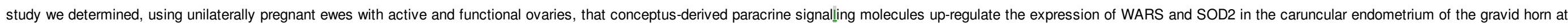

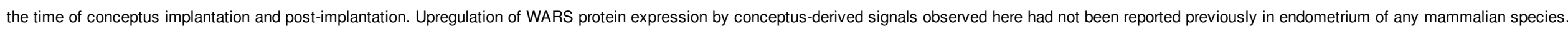

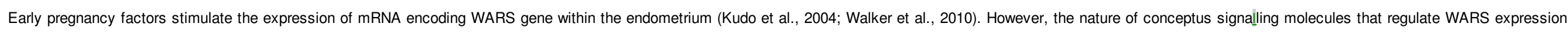

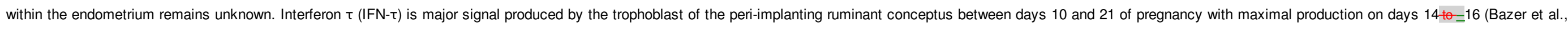

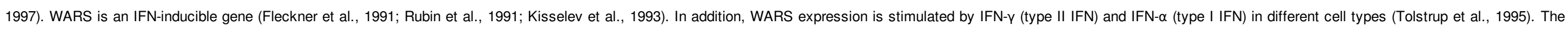

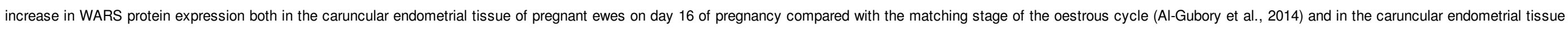

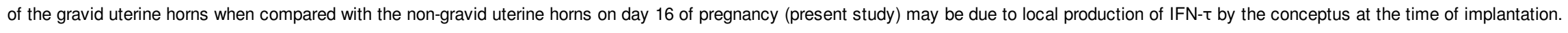

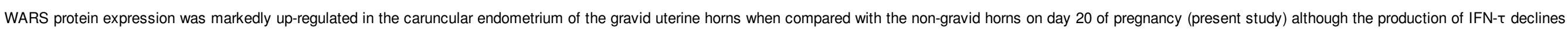

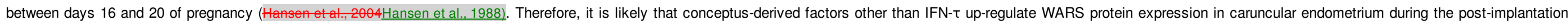

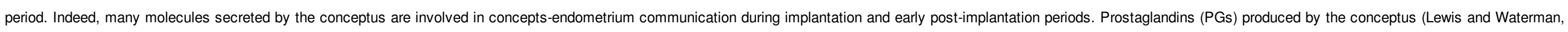




\section{elsevier_BC_4514}

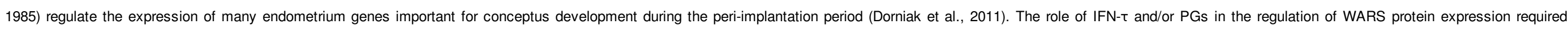
further properly designed in vivo and in vitro experiments.

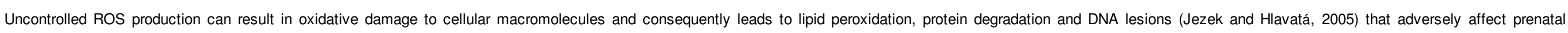

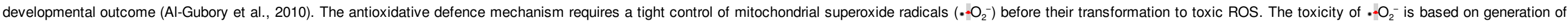

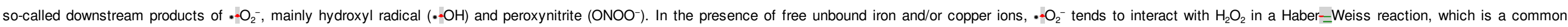

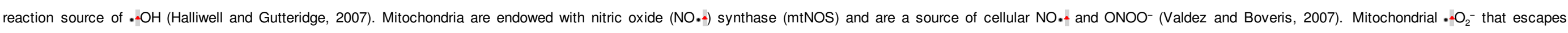

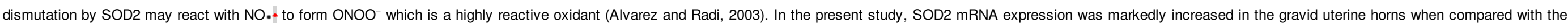

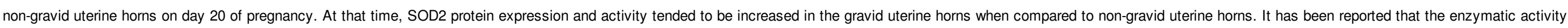

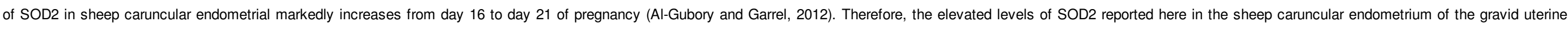

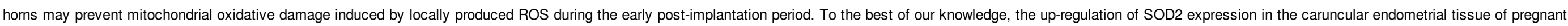
ewes by conceptus-derived factors observed here has not been previously described in the literature.

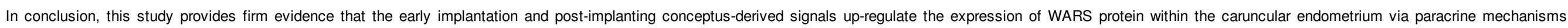

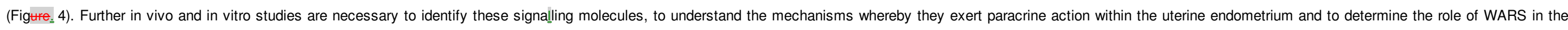
establishment of pregnancy. These findings establish a new reference database and will open the avenue for such studies.

\section{Gravid horn}

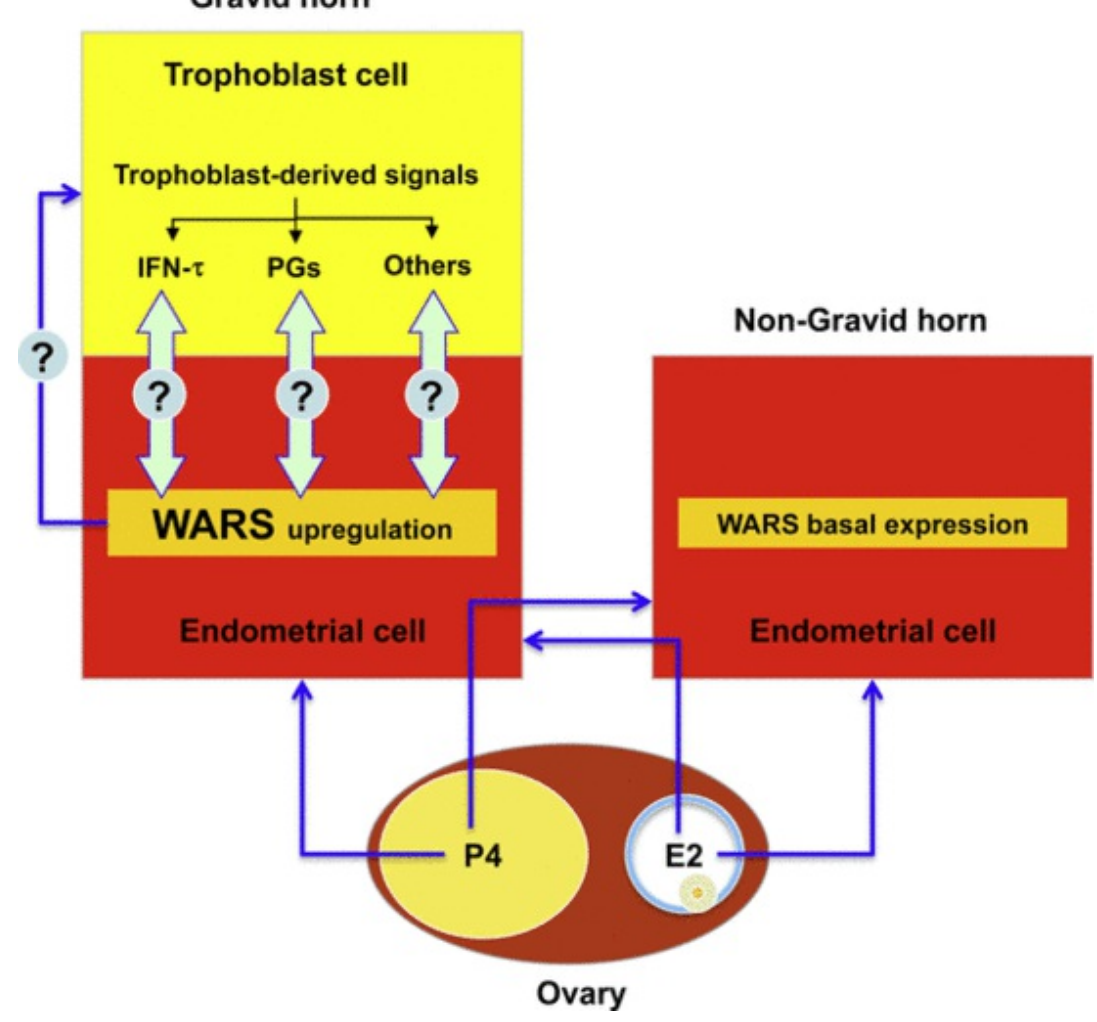

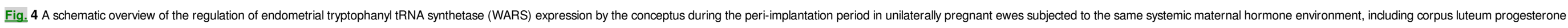

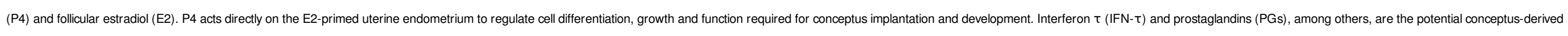




\section{elsevier_BC_4514}

signals that may be involved in the regulation of WARS in the gravid uterine horn.

\section{DeelarationConflict of interest}

The authors declare that there is no conflict of interest that could be perceived as prejudicing the impartiality of the research reported.

\section{Funding}

This research project was funded by NHS Grampian R\&D (project number RG05/019NHS Grampian R\&D (project number RG05/019).

\section{Author contributions}

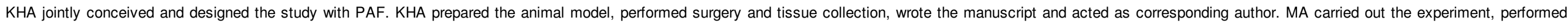

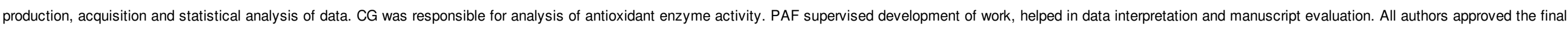
version of manuscript.

\section{Acknowledgements}

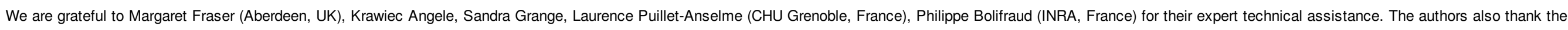
staff of the sheep sheds of Jouy-en-Josas (INRA, France) for outstanding technical help and sheep management.

\section{Appendix A. Supplementary data}

Supplementary data associated with this article can be found, in the online version, at http://dx.doi.org/10.1016/j.biocel.2014.12.013.

\section{References}

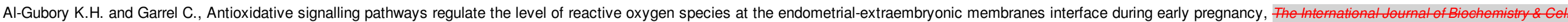
Biology Int J Biochem Cell Biol 44, 2012, 1511-1518.

Al-Gubory K.H., Bolifraud P. and Garrel C., Regulation of key antioxidant enzymatic systems in the sheep endometrium by ovarian steroids, Endocrinology 149, 2008, 4428-4434.

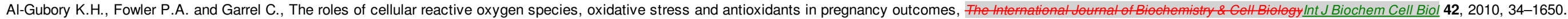

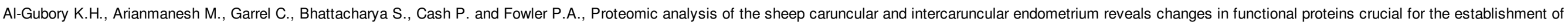
pregnancy, Reproduction 147, 2014, 599-614.

Alvarez B1 and Radi R., Peroxynitrite reactivity with amino acids and proteins, Amino Acids 25, 2003, 295-311.

Barnes F.L., The effects of the early uterine environment on the subsequent development of embryo and fetus, Theriogenology 53, 2000, 649-658.

Bazer F.W., Spencer T.E. and Ott T.L., Interferon tau: a novel pregnancy recognition signal, American dournal of Reproductive Immunology J Reprod Immunol 37, 1997, 412-420.

Bazer F.W., Roberts R.M., Basha S.M., Zavy M.T., Caton D. and Barron D.H., Method for obtaining ovine uterine secretions from unilaterally pregnant ewes, Jurnal ofAnimal Seienee Anim Sci 49, 1979, 1522-1527.

Diskin M.G. and Morris D.G., Embryonic and early foetal losses in cattle and other ruminants, Reproduetion in Domestic Animals43Suppt Domest Anim $\underline{43}$ (Suppl. 2), $2008,260-267$.

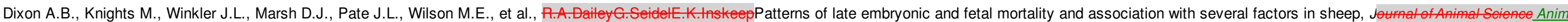
Sci $85,2007,1274-1284$

Dorniak P., Bazer F.W. and Spencer T.E., Prostaglandins regulate conceptus elongation and mediate effects of interferon tau on the ovine uterine endometrium, Biology of Reproduetion Reprod 84, 2011, 1119-1127.

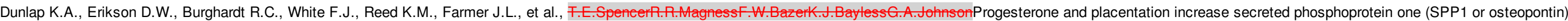




\section{elsevier_BC_4514}

in uterine glands and stroma for histotrophic and hematotrophic support of ovine pregnancy, Biology ofreproduction Reprod 79, 2008, 983-990.

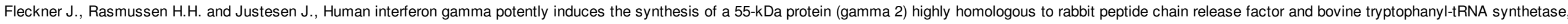
Procedings of the National Academy of Sciences Natl Acad Sci 88, 1991, 11520-11524.

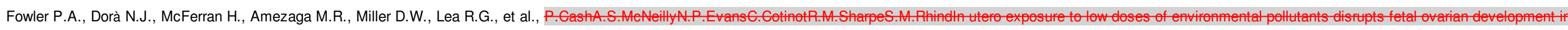
sheep Molecular Human Reproduetionln utero exposure to low doses of environmental pollutants disrupts fetal ovarian development in sheep, Mol Hum Reprod 14, 2008, 269-280.

Halliwell B. and Gutteridge J.M.C., Free Radicals in Biology and Medicine, fourth ed4th ed., 2007, Clarendon Press; Oxford, UK.

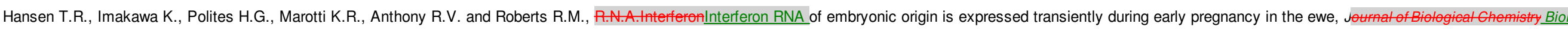
Chem 263, 1988, 12801-12804.

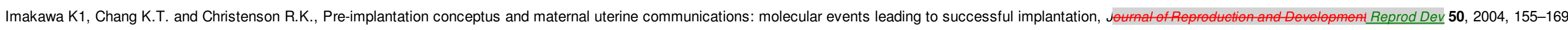
Jezek P. and Hlavatá L., Mitochondria in homeostasis of reactive oxygen species in cell, tissues, and organism, The mternational Journal of Biochemistry \& Coll Biology/nt J Biochem Cell Biol 37, 2005, 2478-2483.

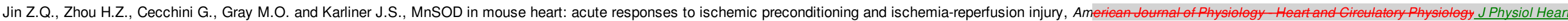
Circ Physiol 288, 2005, H2986-H2994.

Kisselev L., Frolova L. and Haenni A.L., Interferon inducibility of mammalian tryptophanyl-tRNA synthetase: new perspectives, Trends in Biochemical SciencesBiochem Sci 18, 1993, 263-267.

Kudo Y., Hara T., Katsuki T., Toyofuku A., Katsura Y., Takikawa O., et al., F.Fujiik. OhamaMechanisms regulating the expression of indoleamine 2,3-dioxygenase during decidualization of human endometrium, Human Peproduction Reprod 19, 2004, 1222-1230

Lewis G.S. and Waterman R.A., Metabolism of arachidonic acid in vitro by ovine conceptuses recovered during early pregnancy, Prostaglandins 30, 1985, 263-283.

Lowry O.H., Rosebrough N.J., Farr A.L. and Randall R.F., Protein measurement with fFolin phenol reagent, The dournal of Biological Chomistry J Biol Chem 193, 1951, 265-275.

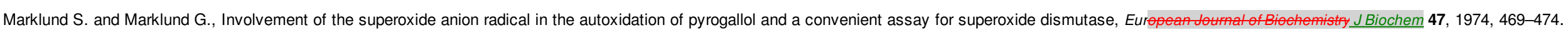

Moor R.M. and Rowson L.E., Local maintenance of the corpus luteum in sheep with embryos transferred to various isolated portions of the uterus, Journal of Reproduction and Fertility Reprod Fertil 12, 1966, 539-550.

Orrenius S., Gogvadze V. and Zhivotovsky B., Mitochondrial oxidative stress: implications for cell death, Annual Reviow of Pharmacology and Toxicology Rev Pharmacool Toxicol 47, 2007, 143-183.

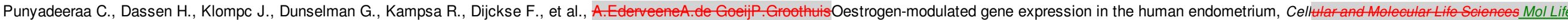
Sci 62, 2005, 232-250.

Rubin B.Y., Anderson S.L., Xing L., Powell R.J. and Tate W.P., Interferon induces tryptophanyl-tRNA synthetase expression in human fibroblasts, The dournal of Biological Chemistry Jiol Chem 1266, 1991, 24245-24248.

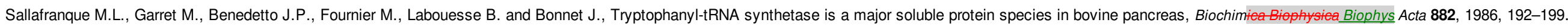

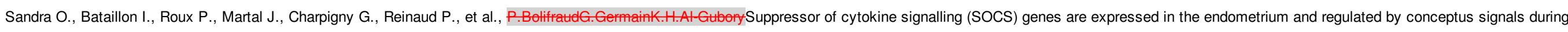
early pregnancy in the ewe,

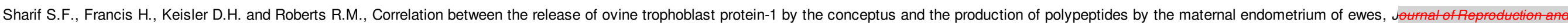

Fertility Reprod Fertil 85, 1989, 471-476.

Spencer T.E., Johnson G.A., Bazer F.W. and Burghardt R.C., Implantation mechanisms: insights from the sheep, Reproduction 128, 2004, 657-668.

Sugino N., The role of oxygen radical-mediated signaling pathways in endometrial function, Placenta $\underline{28}$ (Suppl. A), 2007, S133-S136. 


\section{elsevier_BC_4514}

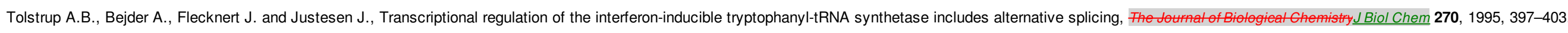

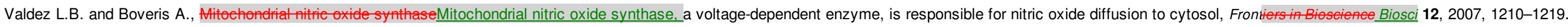
Vigano P., Mangioni S., Pompei F. and Chiodo I., Maternal-conceptus cross talk-A_a review, Placenta 24, 2003, S56-S61.

Walker C.G., Meier S., Littlejohn M.D., Lehnert K., Roche J.R. and Mitchell M.D., Modulation of the maternal immune system by the pre-implantation embryo, BMC Genomics 11, $2010,474$.

\section{Appendix A. Supplementary data}

The following are the supplementary data to this article:

Multimedia Component 1

\section{Queries and Answers}

Query: Please confirm that given names and surnames have been identified correctly.

Answer: approved

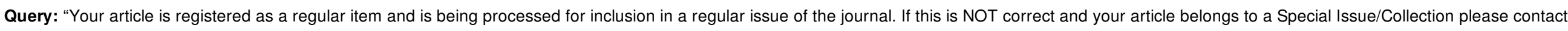
k.mottram@elsevier.com immediately prior to returning your corrections.".

Answer: approved

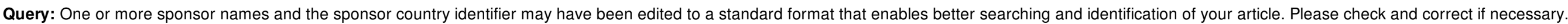
Answer: approved 